\title{
EFEITO DO TEOR DE MANGANÊS NA EVOLUÇÃO MICROESTRUTURAL E NA CINÉTICA DA TRANSFORMAÇÃO BAINÍTICA INCOMPLETA, EM UM AÇO DE ALTO CARBONO
}

\author{
Daniele da Silva ' \\ Vitor Ogliari ${ }^{2}$ \\ Carlos Augusto Silva de Oliveira ' \\ Modesto Hurtado Ferrer ${ }^{3}$ \\ Marcio Ferreira Hupalo ${ }^{4}$
}

\section{Resumo}

Neste trabalho foram estudadas duas ligas de aço fundidas e conformadas a quente, variando os teores de manganês (I,50\% e I,98\%), a fim de verificar seu efeito na morfologia e cinética da transformação bainítica incompleta durante austêmpera realizada a $280{ }^{\circ} \mathrm{C}$ por tempos entre Imin a $839 \mathrm{~h}$. As temperaturas Bs e Ms foram determinadas a partir de simulações, utilizando o software JMat-Pro ${ }^{\circledR}$. Verificou-se a presença de austenita retida na forma de filmes e blocos, associada a presença de ripas de ferrita bainítica, como principais produtos da transformação bainítica em ambos os aços. Para a liga $B$, com maior teor de manganês, as frações volumétricas de austenita retida são maiores do que na liga $A$, independentemente do tempo de tratamento, devido ao efeito do manganês em estabilizar a austenita. A liga $B$, na região da estáse da reação bainítica, apresentou menor fração volumétrica de ferrita bainítica (77\%) em comparação com a liga A (85\%); além disso, o tempo para alcançar a estáse na liga B (36h) foi superior quando comparado ao da liga A (20h). Palavras-chave: Aço bainítico; Ferrita bainítica; Manganês; Transformação bainítica.

\section{EFFECT OF MANGANESE IN THE EVOLUTION MICROSTRUCTURAL AND KINETIC OF THE INCOMPLETE BAINITIC TRANSFORMATION IN A HIGH-CARBON STEEL}

\begin{abstract}
In this work were studied two alloy steel, shaped hot, by varying the manganese content (I.50\% and $1.98 \%)$ in order to verify its effect on the morphology and the kinetics of incomplete bainite transformation during austempering, performed at $280^{\circ} \mathrm{C}$ for times ranging from I minute to $839 \mathrm{~h}$. The temperatures Bs and Ms were determined from simulations, using JMat-Pro ${ }^{\circledR}$ software. It was found the presence of retained austenite in the form of films and blocks, associated with the presence of lath bainitic ferrite, as the main products of the bainitic transformation, in both steels. For alloy $B$, with higher manganese content, the volume fraction of retained austenite are higher than in the league $A$, regardless of the time of treatment, due to the effect of manganese to stabilize the austenite. The alloy $B$ in the region of stasis of bainitic reaction showed lower volume fraction of the bainitic ferrite (77\%) compared to Alloy A (85\%); Additionally, the time to reach stasis in Alloy B (36h) was greater when compared to Alloy A (20h).

Keywords: Bainitic steel; Bainitic ferrite; Manganese; Bainitic transformation.

\section{INTRODUÇÃO}

Nos últimos anos, novos aços com alto teor de carbono, contendo elementos de liga como $\mathrm{Si}, \mathrm{Mn}, \mathrm{Cr}, \mathrm{Ni}$ e Mo, vêm sendo desenvolvidos para aplicações, onde se

exijam combinações de resistência à fadiga, tenacidade à fratura e resistência ao desgaste $[1,2]$. Esse comportamento é decorrente do controle da microestrutura durante o

'Universidade Federal de Santa Catarina - UFSC, Campus Universitário, Florianópolis, SC, Brasil. E-mail: daniele.silva@posgrad.ufsc.br

${ }^{2}$ Centro Universitário Sociesc - UNISOCIESC, Joinville, SC, Brasil.

${ }^{3}$ Universidade Federal de Santa Catarina - UFSC, Joinville, SC, Brasil.

${ }^{4}$ Universidade Estadual de Ponta Grossa - UEPG, Ponta Grossa, PR, Brasil.
\end{abstract}

2176-1523/C 2016 Associação Brasileira de Metalurgia, Materiais e Mineração. Publicado pela ABM. Este é um artigo de acesso aberto distribuído sob os termos da licença Creative Commons CC BY-NC-ND (Attribution-NonCommercial-NoDerivs) - https:// creativecommons.org/licenses/by-nc-nd/4.0\%. 
tratamento térmico de austêmpera, pela ocorrência da transformação bainítica incompleta, que resulta na obtenção de uma microestrutura mista que combina ferrita bainítica e austenita retida de alto carbono, de onde surge a denominação destes materiais como aços bainíticos [3].

Nos aços bainíticos de alto carbono é necessário produzir bainita num amplo intervalo de tempo, no patamar isotérmico, para evitar a formação de uma microestrutura mista de bainita e martensita que possa favorecer a formação de trincas de têmpera e, consequentemente, reduzir a resistência ao impacto do material [3].

A transformação bainítica da austenita ocorre em uma faixa de temperatura entre o início da transformação da martensita e as temperaturas de formação da ferrita e perlita $[3,4]$. Nestas condições é possível a obtenção de morfologias provenientes de uma transformação global ou completa ou por morfologias que caracterizam uma transformação parcial ou incompleta [3].

$\mathrm{Na}$ Figura I é apresentado um esquema da curva de cinética de uma transformação de fase típica, em patamar isotérmico, destacando-se as principais etapas nas quais

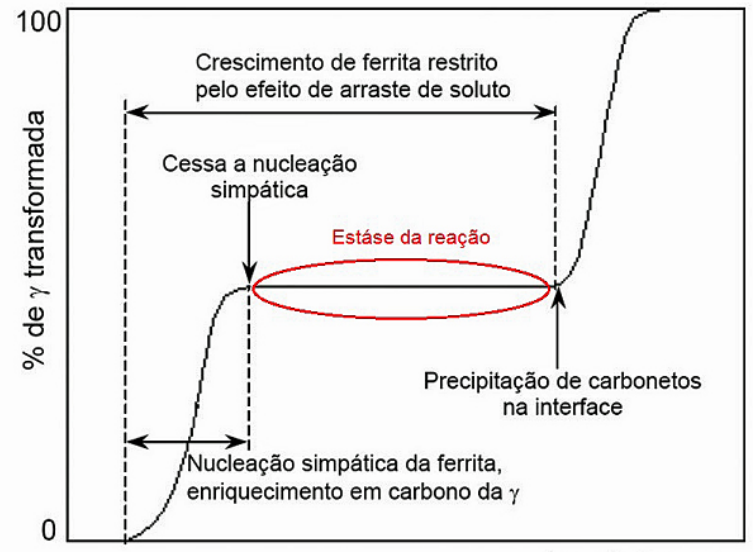

Log do tempo

Figura I. Curva cinética da transformação bainítica incompleta, mostrando o fenômeno de estáse da reação [I].

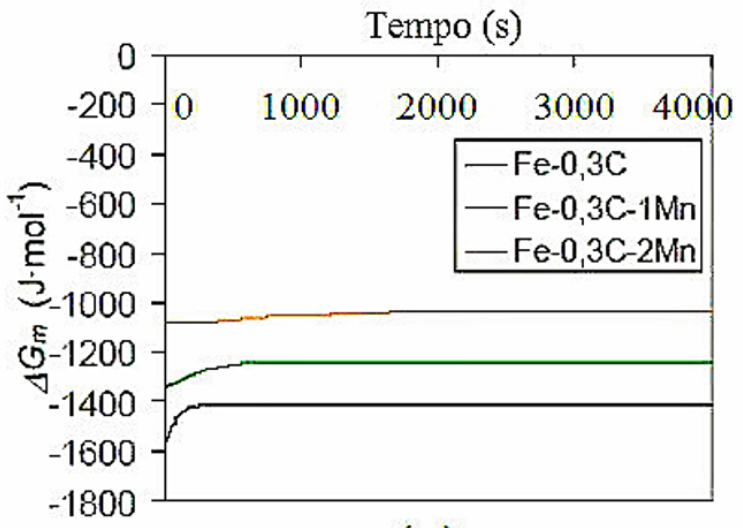

(a) ocorre a transformação bainítica incompleta de um aço. A transformação cessa quase que completamente e, assim, pode permanecer por longos períodos na temperatura de tratamento. A precipitação de carbonetos é retardada pela presença de elementos de liga, tais como silício, manganês e níquel.

Devido ao efeito de arraste de soluto há uma diminuição na velocidade de migração das interfaces, proposto por Kisman e Aaronson [5] e aprimorado por Purdy e Brechet [6]. Este efeito faz com que a migração de interfaces praticamente cesse, logo após a nucleação. Um superresfriamento posterior pode permitir a nucleação de subunidades a partir da própria interface $\alpha / \gamma$, pelo processo de nucleação simpática. A nucleação simpática é interrompida pela partição de carbono para a austenita, provocando a diminuição do potencial para nucleação e a formação do patamar característico do fenômeno de estáse [3,4].

$\mathrm{Na}$ Figura 2, são apresentadas curvas de cinéticas de transformação de fase em aços com diferentes teores de manganês. A liga com menor teor de manganês possui menor valor inicial e final de energia de ativação e como consequência um aumento na velocidade da transformação de fase [7].

As principais aplicações destes aços incluem: componentes forjados de vários tamanhos, desde pequenos parafusos e eixos de transmissão para veículos até grandes rotores para turbinas de geradores de energia. Outro campo de aplicações é a fabricação de rodas para trens de carga e de alta velocidade para passageiros, bem como componentes que requerem resistência ao desgaste, como pistas de mancais de rolamentos, especialmente em condições de baixa lubrificação [8-10].

Diante deste contexto, nesse trabalho estudou-se a influência do manganês nos aspectos morfológicos e cinéticos da transformação bainítica incompleta, em aços de alto carbono, austemperados à temperatura de $280^{\circ} \mathrm{C}$, em tempos variando entre I min e $839 \mathrm{~h}$, utilizando-se de microscopia óptica (MO) e eletrônica de varredura (MEV) para a caracterizar a evolução microestrutural.

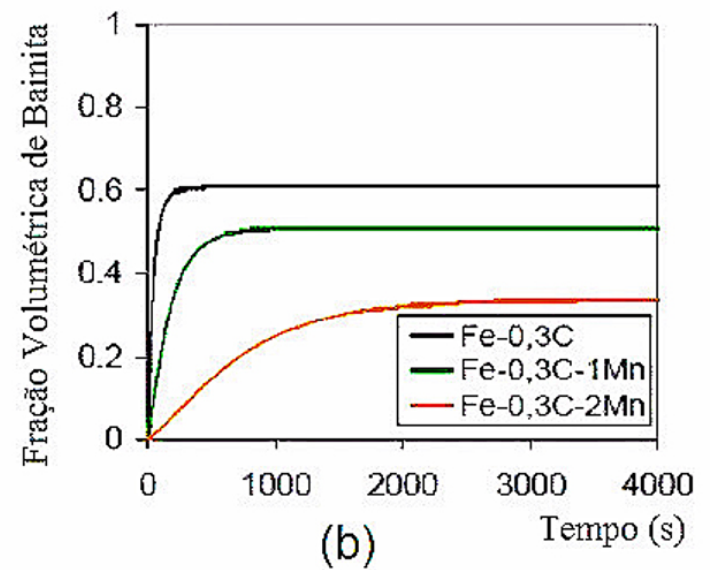

Figura 2. Evolução da transformação bainítica em ligas Fe-0,3C; Fe-0,3C-IMn e Fe-0,3C-2Mn; (a) Diagrama de energia de ativação em função do tempo; (b) Curva cinética da transformação bainítica [7]. 


\section{MATERIAIS E MÉTODOS}

Para o desenvolvimento do estudo foram utilizadas duas ligas de aço de alto carbono, fundidas a partir de blocos "Y" no Setor de Fundição do Centro Universitário Sociesc - UNISOCIESC, atendendo às especificações da norma ASTM A897. Buscando avaliar a influência do manganês (Mn), variou-se a composição química conforme apresentado na Tabela I (\% em peso).

Variaram-se, fundamentalmente, os teores de manganês (Mn) para avaliar seu efeito potencial na estabilidade da austenita ao longo das etapas do tratamento de austêmpera. Além do Mn outros elementos, como silício, níquel e cromo foram adicionados de maneira controlada que podem de maneira substancial exercer sua influência sobre os comportamentos cinéticos e morfológicos da transformação de fase.

A partir da área útil dos blocos fundidos, obtiveram-se tarugos com dimensões de $200 \times 40 \times 40 \mathrm{~mm}$ que foram submetidos à conformação a quente, consistindo em dois passes com reduções de $50 \%$ e $30 \%$ nas temperaturas de $960 \pm 20^{\circ} \mathrm{C}$ e $870 \pm 20^{\circ} \mathrm{C}$, no primeiro e segundo passe, respectivamente; obtendo-se como produto final chapas de $7 \mathrm{~mm}$ de espessura. A conformação foi realizada com o intuito condicionar o material de partida, resultando em uma microestrutura mista constituída por escassas regiões de perlita fina, ripas de ferrita bainítica nucleadas cooperativamente, definindo pequenos agrupamentos ou pacotes de feixes de ferrita bainítica, que são predominantes em cada um dos aços, associados à presença de bandas de martensita massiva, caracterizando um estado de têmpera ao ar seguido da laminação a quente, conforme Figura 3.

A partir das chapas obtidas por laminação foram usinados corpos de prova (CP) com dimensões finais

Tabela I. Teores dos principais elementos de liga nas ligas (A) e (B)

\begin{tabular}{ccccccc}
\hline Liga & $\% \mathbf{C}$ & $\% \mathbf{M n}$ & $\% \mathbf{~ S i}$ & $\% \mathbf{~ N i}$ & $\% \mathbf{C r}$ & $\% \mathbf{M o}$ \\
\hline (A) & 0,85 & $\mathbf{I}, \mathbf{5 0}$ & $\mathrm{I}, 48$ & 0,50 & $\mathrm{I}, 30$ & 0,30 \\
(B) & 0,85 & $\mathbf{1 , 9 8}$ & $\mathrm{I}, 5 \mathrm{I}$ & 0,48 & $\mathrm{I}, 38$ & 0,30 \\
\hline
\end{tabular}

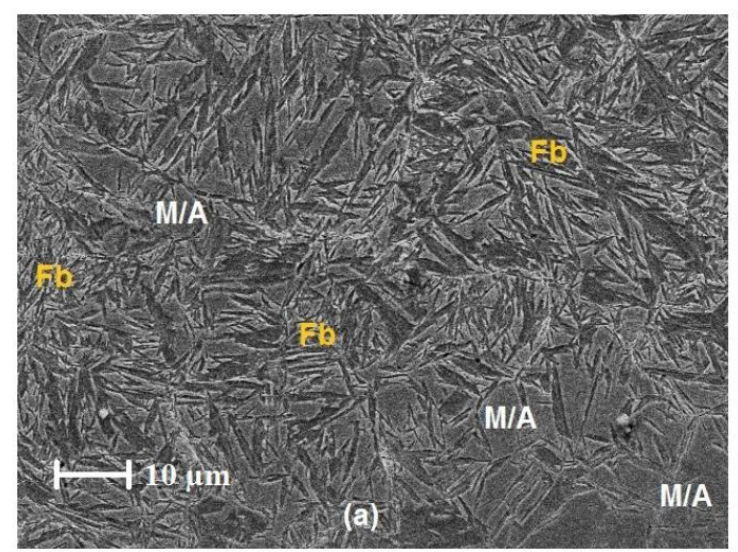

de $6 \times 8 \times 10 \mathrm{~mm}$, para a realização dos experimentos de tratamento térmico.

O ciclo de tratamento térmico consistiu em austenitizar as duas ligas à temperatura de $870^{\circ} \mathrm{C}$ por $\mathrm{Ih}$, antecedido de pré-aquecimento a $450^{\circ} \mathrm{C}$ por $0,5 \mathrm{~h}$, seguido de um resfriamento controlado com estágio isotérmico a $280^{\circ} \mathrm{C}$, com tempos de permanência que variaram entre I min e $839 \mathrm{~h}$, conforme representado na Figura 4.

Após o tratamento de austêmpera, foram realizadas análises microestruturais por microscopia óptica (MO) e eletrônica de varredura (MEV). A preparação metalográfica foi realizada de acordo com os métodos convencionais, compreendendo lixamento até a grana \# I 200, seguido do polimento com pasta diamantada de 3 e I $\mu \mathrm{m}$. $O$ ataque metalográfico foi realizado utilizando-se os reagentes de Le Pera [I I ] e Picral 4\%. Buscando atender à necessidade de quantificação das microestruturas, para fins de estudo de cinética das transformações de fase, foram testadas diversas condições de ataque metalográfico. $O$ objetivo principal destes testes foi encontrar a melhor condição de contraste para identificação das fases presentes na microestrutura.

A análise quantitativa das fases foi realizada no ambiente do programa Image-ProPlus, no módulo MaterialsPro, com a ferramenta Measure Phases, acoplado a um microscópio óptico da marca Olympus BX5 I no Laboratório de Materiais da UNISOCIESC. Durante as medidas quantitativas, foram analisados, em média, de cinco a sete campos por região e por amostra, com aumentos entre 500 e 1000 vezes, dependendo da fração volumétrica das fases de interesse e do grau de refinamento da microestrutura. Amostras com características semelhantes foram analisadas segundo os mesmos critérios. $O$ método-padrão desenvolvido no presente trabalho utilizou duas faixas de "threshold" destinadas à quantificação de: i) ferrita bainítica e ii) austenita retida / martensita. O software quantifica as fases escolhidas por diferenças de cores, com auxílio de uma ferramenta que possibilita o ajuste e definição dos intervalos de tonalidades. Após a definição dos parâmetros citados anteriormente, pode-se executar a análise "Run". A Figura 5 ilustra um

Figura 3. Microestrutura das amostras conformadas a quente: (a) liga A; (b) liga B. Microscopia eletrônica de varredura (MEV). Ataque Picral 4\%. Aumento de I000X. Legenda: Fb (ferrita bainítica) e M/A (martensita e/ou austenita). 
exemplo no ambiente do software ImagePro-Plus ${ }^{T M}$ para contagem de fases.

A análise por microscopia eletrônica de varredura (MEV) foi realizada em um microscópio da marca Shimadzu, modelo SSX-550 Superscan no Departamento de Engenharia de Materiais da UEPG.

Para obtenção das curvas de transformação de fase (TTT), para as duas ligas estudadas, foram realizadas simulaçóes numéricas através do software JMatPro ${ }^{\circledR}$. Ao calcular e minimizar a energia livre de Gibbs de um sistema (delimitado pelo usuário), o software pode estimar a composição e as frações volumétricas das fases presentes. A confiabilidade dos resultados é função dos dados disponíveis para os vários subsistemas envolvidos no cálculo. $\bigcirc$ JMatPro ${ }^{\circledR}$ é capaz de prever cinética e termodinamicamente vários sistemas e constitui a base de modelagem cinética deste estudo. As referidas simulações foram realizadas no Instituto SENAI de Inovação em Laser, em Joinville-SC.

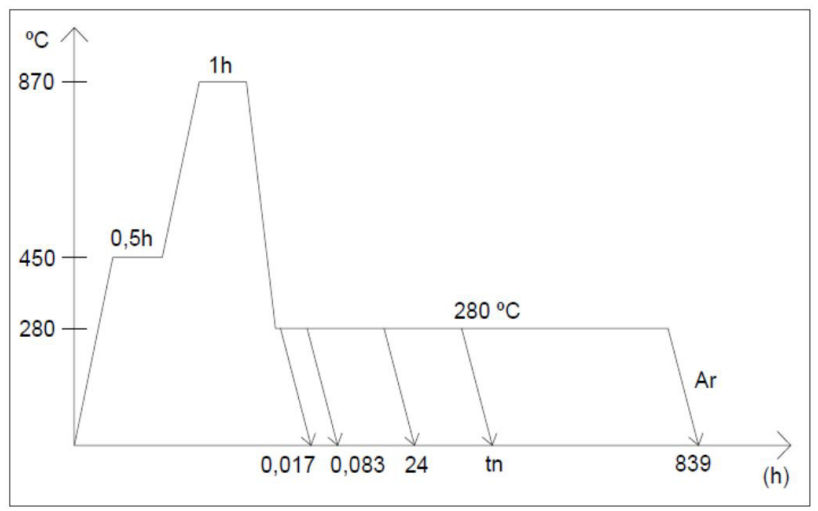

Figura 4. Representação esquemática do tratamento térmico de austêmpera.

\section{RESULTADOS E DISCUSSÕES}

\section{I Aspectos Morfológicos da Transformação de Fase}

A análise morfológica irá descrever os principais estágios que ocorreram na transformação dos corpos de prova austemperados. Nos menores tempos de austêmpera, entre I min e $2 \mathrm{~h}$, as microestruturas mostraram-se totalmente martensíticas, não sendo evidenciada presença de ferrita bainítica. Isto se deve à presença de elementos de liga como $\mathrm{Mn}, \mathrm{Ni}$ e $\mathrm{Cr}$ que deslocam as curvas TTT para a direita (tempos mais longos), retardando assim o início da nucleação da ferrita bainítica.

A partir de $2 \mathrm{~h}$ de austêmpera é possível observar na liga $A$ (Figura 6a) a presença de feixes de ferrita bainítica dispersos em uma matriz ainda composta predominantemente por austenita e martensita. Já na liga B (Figura 6b), para o mesmo tempo de austêmpera não há evidências destes aspectos.

$\mathrm{Na}$ Figura 6a, pode ser observado o início discreto da nucleação da ferrita bainítica, regióes em destaque, esses feixes iniciam a nucleação a partir dos contornos da austenita prévia. Segundo Bhadeshia [3], esse fenômeno ocorre com a partição do carbono para a austenita, reduzindo a temperatura de início da transformação da martensita durante o resfriamento. Para a Liga B, com maior teor de manganês, a Figura $6 \mathrm{~b}$ ilustra o retardo no início da nucleação da ferrita bainítica, uma vez que a microestrutura apresentada ainda é constituída por uma matriz martensítica. Deve-se considerar o efeito inibidor do manganês na formação da ferrita durante o resfriamento, uma vez que este elemento dificulta o enriquecimento de carbono desta fase.

A partir do tempo de 36h (Figura 7), observa-se que as ligas já estão com suas microestruturas predominantemente compostas por ferrita bainítica e austenita retida. Esta é a

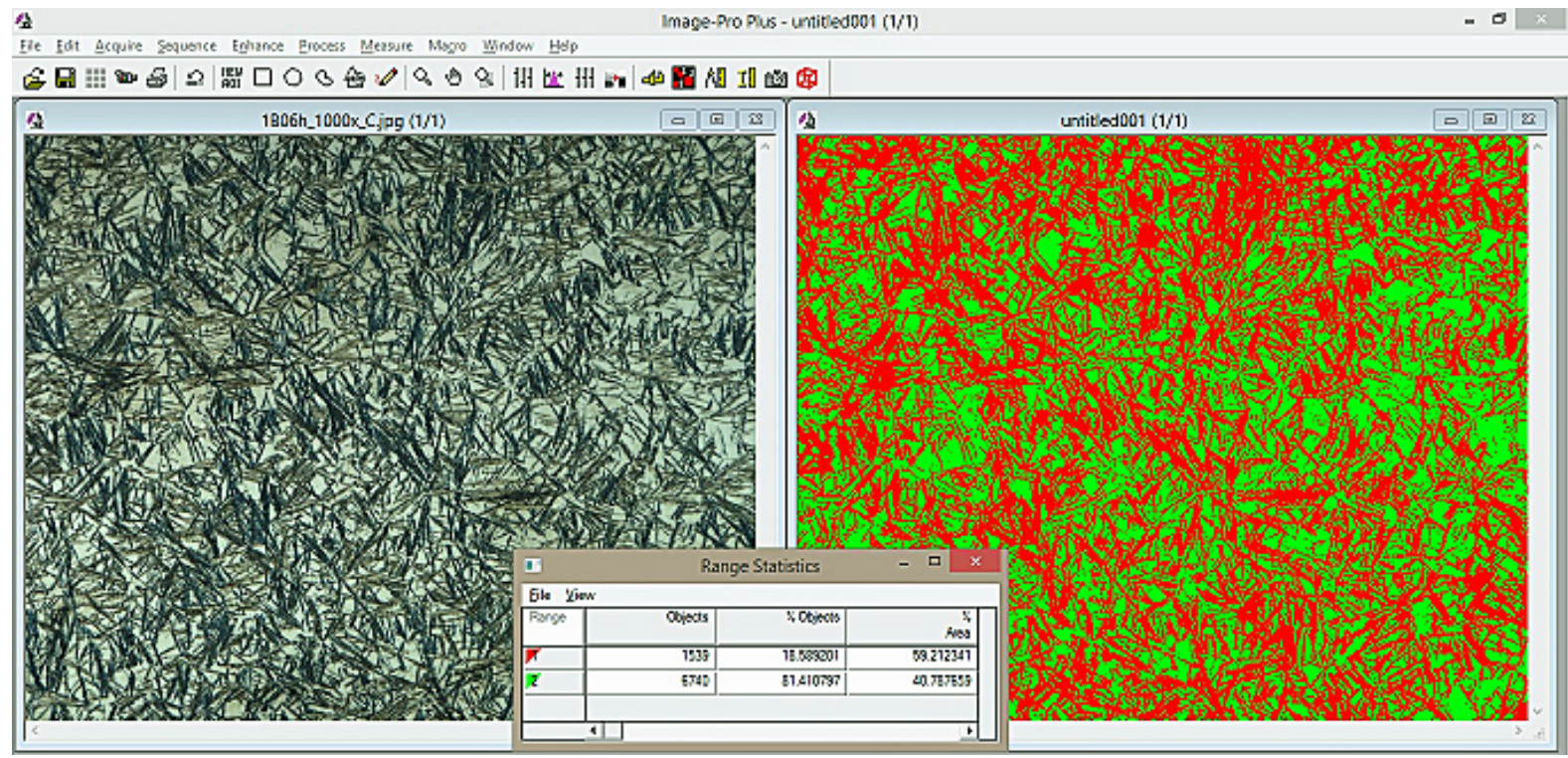

Figura 5. Ambiente de análise do ImagePro-Plus ${ }^{T M}$. 


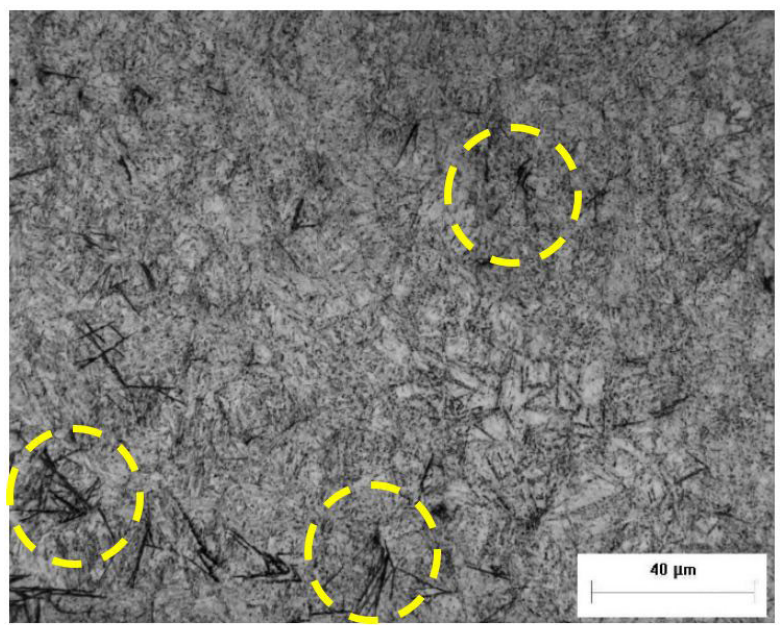

(a)

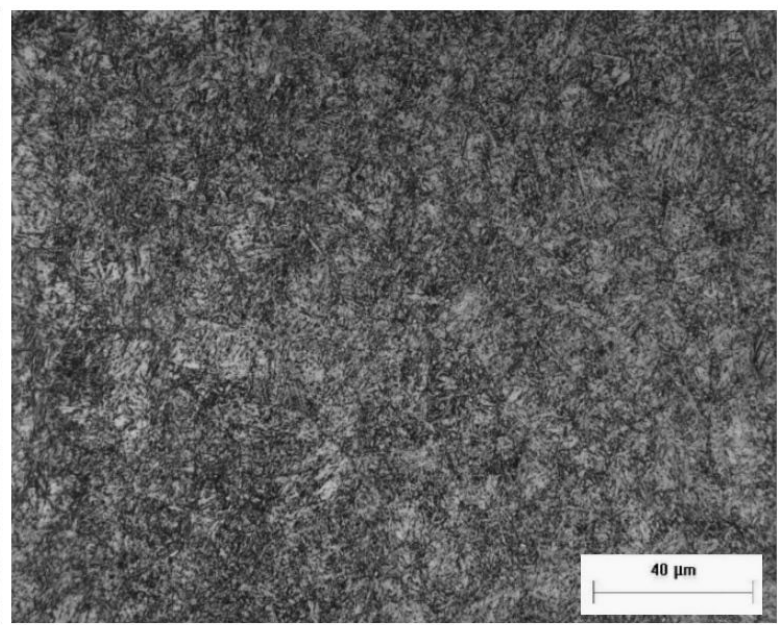

(b)

Figura 6. Microestruturas de amostras austemperadas por $2 \mathrm{~h}$, sendo (a) liga A; e (b) liga B. Microscopia óptica (MO). Ataque Le Pera. Aumento de $1000 X$.

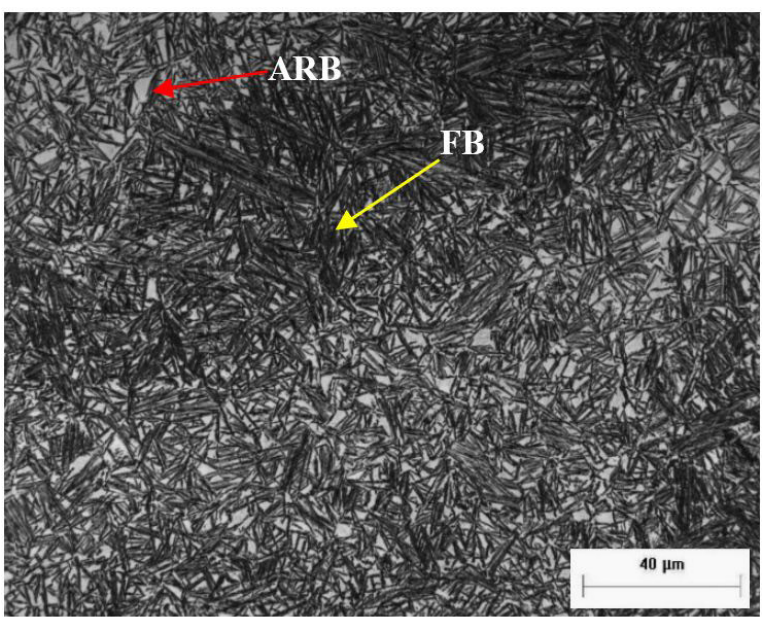

(a)

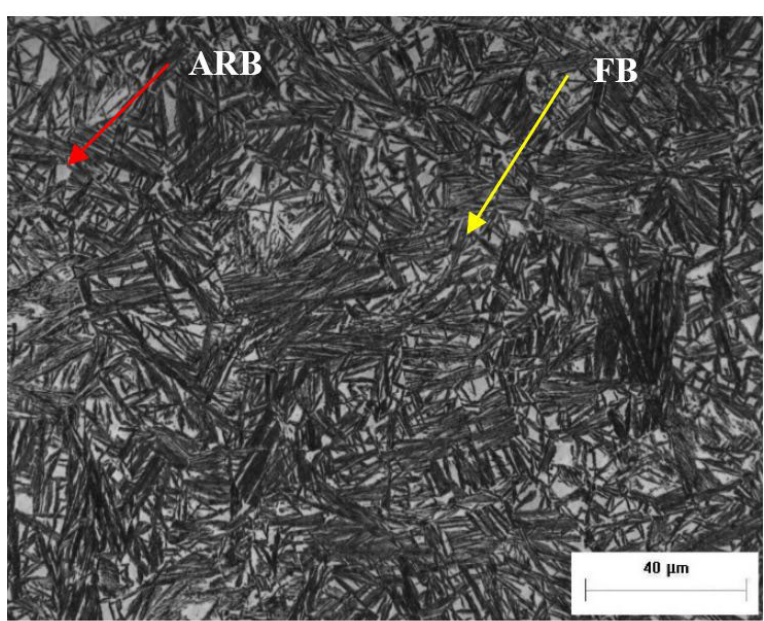

(b)

Figura 7. Microestruturas de Amostras austemperadas a 36h, sendo (a) liga A; e (b) liga B. Microscopia óptica (MO). Ataque Le Pera. Aumento de I000X. Legenda: ARB - austenita retida em forma de blocos; FB - ferrita bainítica.

última etapa do processo de transformação de fase estudado neste trabalho, referindo-se ao estágio de estáse da reação bainítica, resultante do aumento da fração transformada (vide Figura I), momento em que a transformação praticamente cessa devido à baixa energia livre das fases resultantes e ao fenômeno de saturação de carbono na austenita.

$\mathrm{Na}$ Figura 7 as ligas apresentam uma microestrutura constituída por agrupamentos de feixes de ripas de ferrita bainítica em uma matriz formada por blocos de austenita não transformada e retida à temperatura ambiente. A liga $B$ (Figura 7b), com maior teor de manganês, apresenta uma menor fração transformada de ferrita bainítica em comparação com a liga $\mathrm{A}$ (Figura 7a), devido à estabilização da austenita provocada pelo manganês, diminuindo a velocidade de transformação, conforme discutido anteriormente.
A Figura 8 ilustra as microestruturas das ligas austemperadas nos tempos de $240 \mathrm{~h}$ e $839 \mathrm{~h}$. Nestas micrografias é possível observar os produtos da transformação de fase: feixes de ferrita bainítica e austenita retida na forma de filmes e blocos.

A semelhança dos aspectos observados nas microestruturas da Figura 7, para o tempo de 36h, pode-se sugerir que a reação bainítica ainda se encontra na região de estáse. Comparando-se as microestruturas da Figura 8, se observa a mesma tendência em relação à fração transformada para o tempo de 36h (Figura 7), isto é, uma maior fração volumétrica de ferrita bainítica para o menor teor de manganês (liga A, Figura 8a e 8c). Mais uma vez destaca-se o efeito do manganês em estabilizar a austenita, reduzir a velocidade de transformação e inibir a formação de cementita, mesmo para tempos longos de tratamento. 


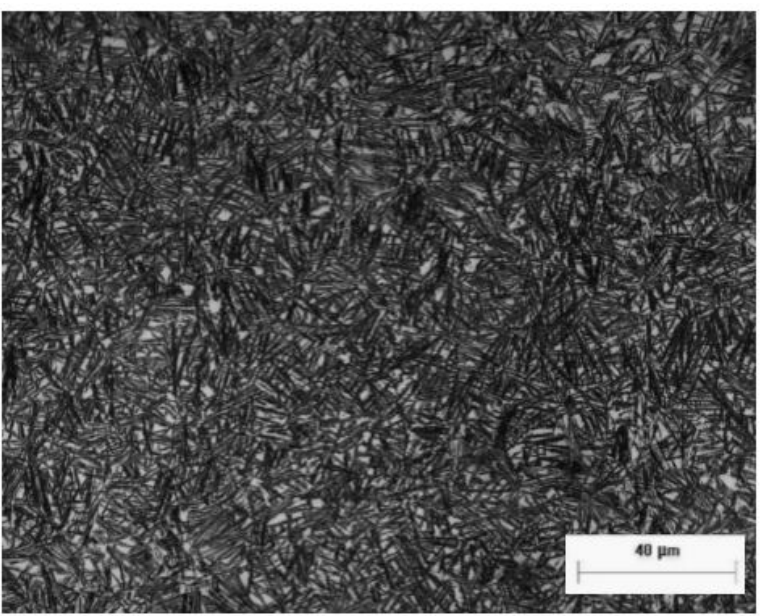

(a)

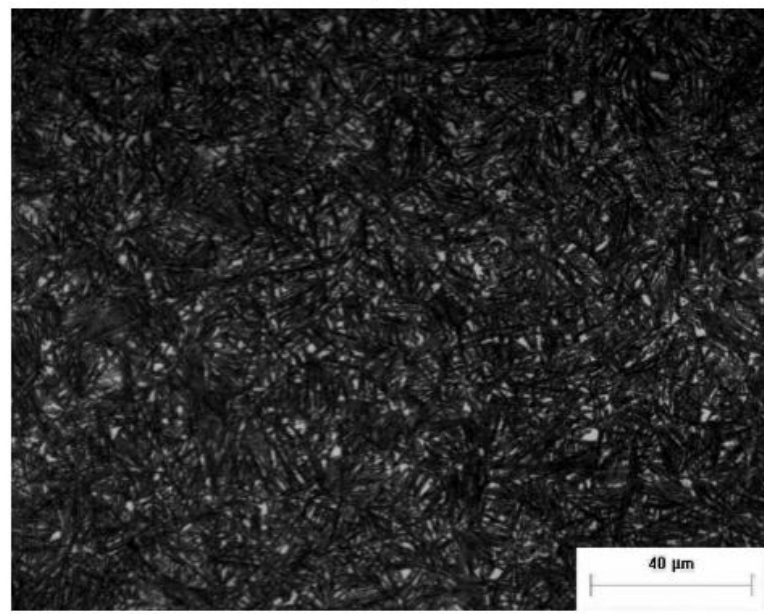

(c)

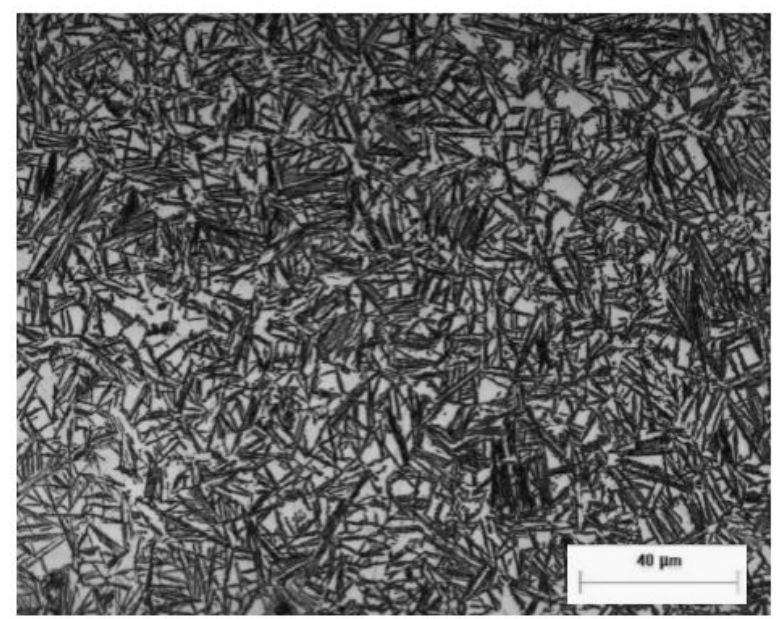

(b)

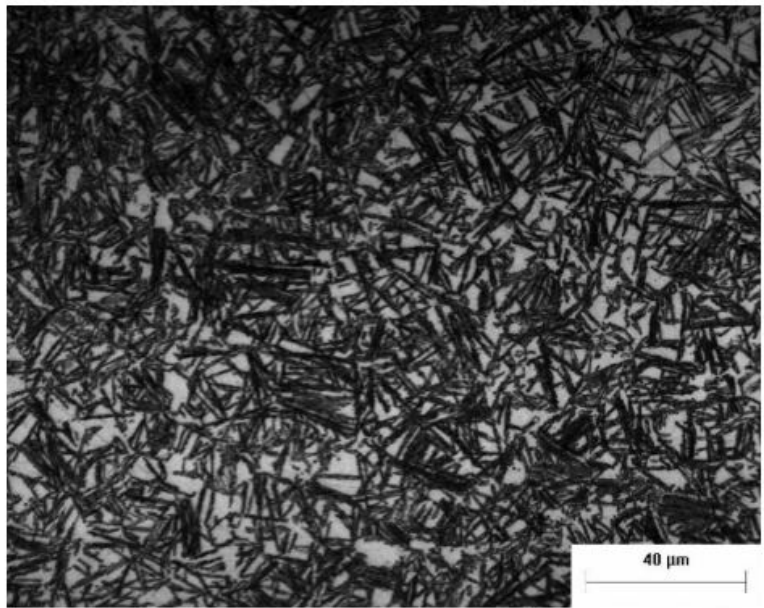

(d)

Figura 8. Microestruturas de amostras austemperadas por 839h, sendo (a) liga A - 240h; (b) liga B - 240h; (c) liga A -839h; (d) liga B - 839h. Microscopia óptica (MO). Ataque Le Pera. Aumento de I000X.

As dimensões das ripas individuais de ferrita, em torno de $200 \mathrm{~nm}$, são equivalentes ao máximo valor teórico de resolução da técnica de microscopia óptica, que é constante e associado ao comprimento de onda da luz visível [3]. Sendo assim, ao microscópio óptico, só é possível observar os agrupamentos de subunidades ou feixes de ripas de ferrita bainítica. Maiores detalhes da microestrutura das ligas podem ser observados nas imagens da Figura 9, obtidas por MEV.

Nas microestruturas da Figura 9, podem-se observar, em maiores detalhes, a presença de austenita retida nas regiões de encontro de diferentes agrupamentos de feixes de ripas de ferrita bainítica (sigla Fb).

Essa austenita retida geralmente possui forma triangular ou poliédrica e é denominada de austenita retida em blocos (sigla ARB). Nas imagens obtidas em microscópio óptico (Figuras 7 e 8) essa austenita aparece na forma de pequenas ilhas claras em meio aos agrupamentos de ripas de ferrita (fase escura). Na micrografia da Figura 9, além de ilhas de austenita retida em blocos (ARB), destaca-se a presença de regiões muito finas de austenita retida entre as ripas (subunidades) dos feixes de ferrita. Essa austenita é comumente denominada de austenita retida em filmes (sigla ARF). Com essa técnica não foi possível observar a presença de carbonetos. A austenita retida em forma de filmes, possui maior estabilidade mecânica e propicia maiores valores de alongamento. Além disso, os filmes de austenita retida localizadas entre as placas de ferrita bainítica, podem aumentar a resistência do material, por transformação em martensita durante $o$ ensaio, também mediante ao efeito TRIP [7].

\subsection{Aspectos Cinéticos da Transformação Bainítica Incompleta}

A cinética da transformação bainítica incompleta foi estudada a partir da quantificação de fases por microscopia ótica (MO) e análise de imagens, utilizando-se a equação de Johnson-Mehl-Avrami-Kolmogorov (JMAK), onde a dependência da fração transformada $(V v)$ com o tempo $(t)$ é dada pela Equação I conforme descrito por Hupalo et al [12], 
e $k$ e $n$ são determinados ajustando-se a equação abaixo aos dados experimentais:

$$
\mathrm{Vv}=1-\exp \left(-\mathrm{k} \cdot \mathrm{t}^{\mathrm{n}}\right)
$$

Na Figura 10, são apresentadas as curvas de cinética de transformação para as duas ligas estudadas. Ambas as curvas de evolução da fração transformada podem ser descritas por uma forma sigmoidal típica, além de apresentarem os patamares característicos do fenômeno de estáse da reação bainítica. Os resultados mostram que a liga B apresenta uma cinética de transformação mais lenta, devido ao atraso no início da nucleação de ferrita bainítica em função do maior teor de manganês ( $1,98 \%$ em peso). Para a liga $A$, com menor teor de manganês ( $I, 50 \%$ em peso), além da maior velocidade de transformação, pode-se observar que o fenômeno de estáse ocorre para uma maior fração transformada.

O maior teor de manganês da liga B aumenta a estabilidade da austenita e desloca as curvas TTT para a direita. Este efeito foi também observado na Figura 2, conforme citado anteriormente.

\subsection{Simulações da Cinética das Transformação Bainítica}

Os resultados das simulações, ilustrados na Figura I I, indicam que a temperatura de início da transformação bainítica para liga $\mathrm{A}$, com menor teor de manganês, é de $410^{\circ} \mathrm{C}$ e para liga $\mathrm{B}$ de $390^{\circ} \mathrm{C}$. Outra informação importante obtida pelas
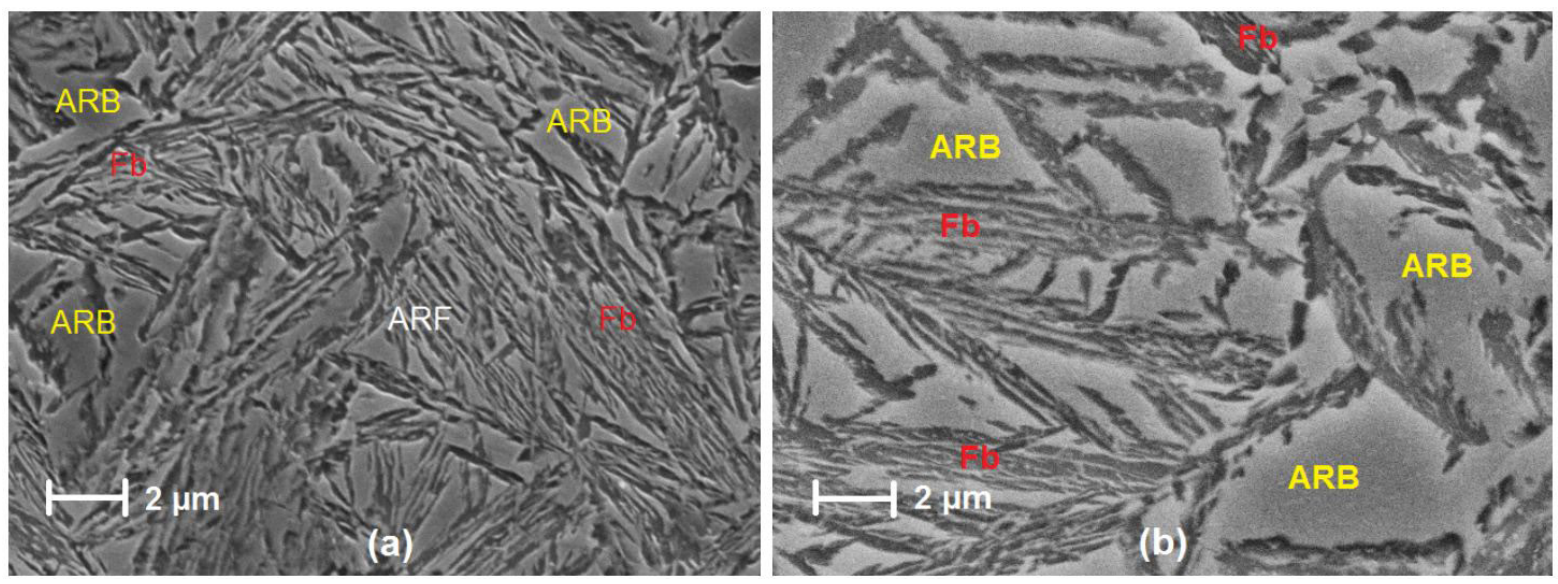

Figura 9. Microestruturas de amostras austemperadas a 839h, sendo (a) liga A; e (b) liga B. Microscopia eletrônica de varredura (MEV). Ataque Picral 4\%. Aumento de 5000X. Legenda: ARB - austenita retida em blocos; ARF - austenita retida em filmes; Fb - ferrita bainítica.

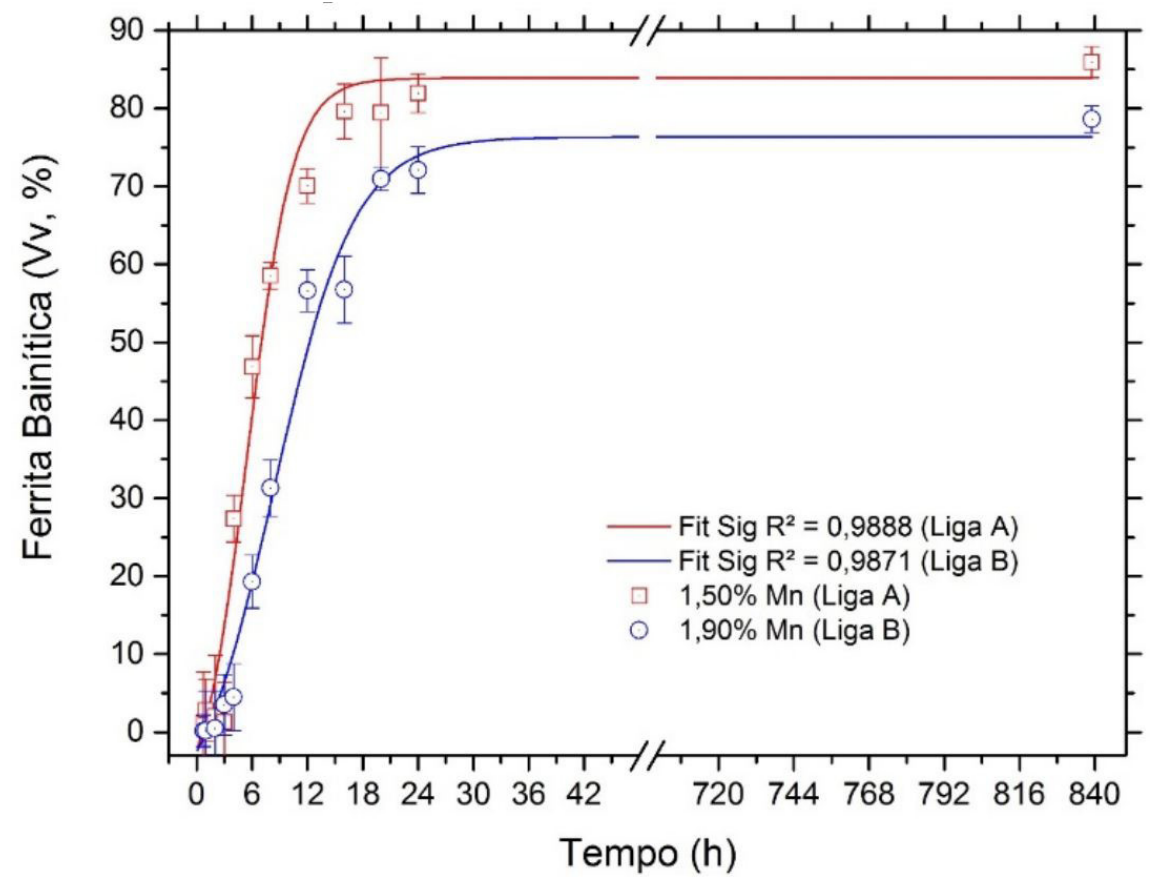

Figura 10. Curvas cinéticas da transformação bainítica incompleta para a liga $\mathrm{A}(\mathrm{I}, 50 \% \mathrm{Mn})$; e liga $\mathrm{B}(\mathrm{I}, 98 \% \mathrm{Mn})$ austemperadas a $280{ }^{\circ} \mathrm{C}$. 

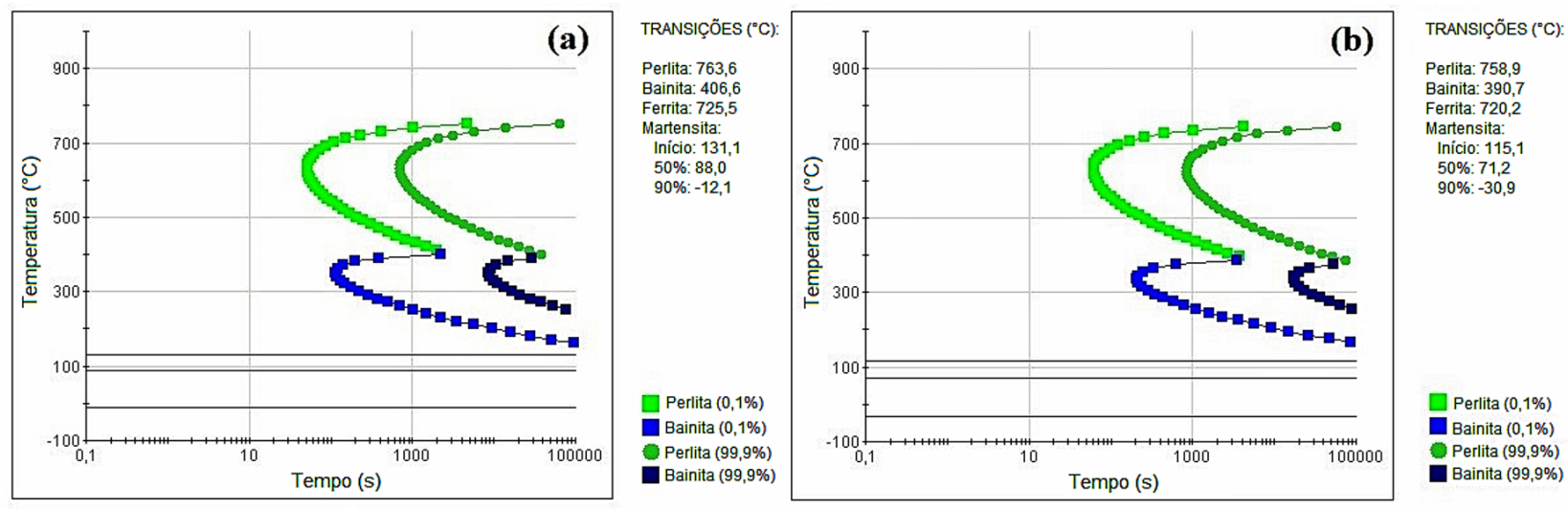

Figura I I. Diagramas TTT obtidos por simulação numérica: (a) liga A; e (b) liga B.

curvas TTT, refere-se ao tempo de início da transformação bainítica que para liga $A$ é de cerca de 550 segundos e para a liga $B$ de cerca de 650 segundos.

Constata-se também o deslocamento para a direita das curvas em $C$ do diagrama TTT na liga $B$ como consequência do maior teor de manganês, indicando seu efeito retardador na decomposição da austenita em ferrita, conforme foi constatado por Bhadeshia [3] e Santofimia [7].

Somando-se ao efeito do manganês no deslocamento para a direita das curvas TTT, na liga B, pode-se considerar o efeito dos demais elementos de liga presentes nos aços estudados, que também afetam a temperabilidade, fazendo com que o tempo para início da transformação seja ainda maior.

\section{CONCLUSÕES}

Para liga $\mathrm{B}$, com maior teor de manganês, teve-se um atraso em relação a liga $A$ na transformação bainítica. $O$ início da nucleação de ferrita bainítica para a liga $B$ foi a partir de $4 \mathrm{~h}$ e para a liga $A$ foi de $2 \mathrm{~h}$. Assim, como o fenômeno de estáse da reação bainítica ocorreu para tempos superiores a $36 \mathrm{~h}$ para a liga $B$ em relação a $20 \mathrm{~h}$ para a liga $A$.

A fração transformada na liga $B$ ficou em torno de $77 \%$ e para a liga A $85 \%$ aproximadamente. A microestrutura é composta por ferrita bainítica e austenita retida, com as técnicas utilizadas não se observou a presença de carbonetos.

A liga $B$, com maior teor de manganês, apresentou uma cinética de transformação mais lenta, caracterizada pelo deslocamento das curvas em $C$ do diagrama TTT para tempos mais longos. Atribuiu-se esse comportamento ao efeito do manganês em estabilizar a austenita, retardando a etapa de nucleação da ferrita bainítica. Os resultados da caracterização microestrutural concordaram com os dados obtidos com o auxílio de simulação numérica.

\section{Agradecimentos}

Ao Instituto SENAI de Inovação, pelo auxílio nos ensaios de simulação numérica utilizando o software JMat-Pro ${ }^{\circledR}$. Ao Fundo de Apoio à Manutenção e ao Desenvolvimento da Educação Superior (FUMDES) de Santa Catarina, pela concessão de bolsas de estudos.

\section{REFERÊNCIAS}

I Caballero FG, Bhadeshia HKDH. Very strong bainite. Current Opinion In Solid And Materials Science, Cambridge. 2004;8(I4):25I-257.

2 Carmo DJ. Obtenção e caracterização de aço fundido bainítico com elevada resistência à fadiga mecânica de alto ciclo [tese de doutorado]. Belo Horizonte: UFMG; 201 I.

3 Bhadeshia HKDH. Bainite in steels. 2. ed. London: IOM Communications IOM Communications; 200 I.

4 Reynolds WT. LI FZ, Shui CK, Aaronson HI. The incomplete transformation phenomenon in Fe-C-Mo alloys. Metallurgical Transactions. A, Physical Metallurgy and Materials Science. 1990;2 IA: I433-I463.

5 Kisman KR, Aaronson $\mathrm{HI}$. Influence of $\mathrm{Al}, \mathrm{Co}$, Si upon the kinetics of the proeutectoid ferrite reaction. Metallurgical Transactions. 1973;4(4):959-967.

6 Purdy GR, Brechet YJM. A solute drag treatment of the effect of alloying elements on the rate of the proeutectoid ferrite transformation in steels. Acta Metallurgica et Materialia. 1995;43:3763-3774. 
Efeito do teor de manganês na evolução microestrutural e na cinética da transformação bainítica incompleta, em um aço de alto carbono

7 Santofimia, NMJ. La transformación bainítica sin formaciónde carburos en aceros [tese de doutorado]. Madri: Universidad Complutense; 2007.

8 Barbacki A. The role of bainite mechanical properties of steels. Elsevier Journal of Materials Processing Technology. 1995;53:57-63.

9 Viáfara CC, Castro MI, Vélez JM, Toro A. Unlubricated sliding wear of pearlitic and bainitic steels. Wear. 2005;259:4II-4I6.

10 Peet MJ, Hill P, Rawson M, Wood S, Bhadeshia HKDH. Fatigue of extremely fine bainita. Materials Science and Technology. 201 I;27(01): I 19-123.

II Le Pera FS. Improved etching technique for the determination of percent martensite in high-strength dual-phase steels. Metallography. 1979;12:263-268.

12 Hupalo MF, Ramos SD, Rabelo A, Batista LN. Aspectos cinéticos e microestruturais da transformação bainítica incompleta em ferros nodulares austemperados. Revista Escola de Minas. 20I2;65(2):2 I 7-224.

Recebido em: 13 Mar. 2016

Aceito em: 21 Jul. 2016 